\title{
Imaginarios de la violencia en el cine mexicano contemporáneo. El caso de Miss Bala de Gerardo Naranjo.
}

\section{Imaginaries of Violence in Contemporary Mexican Cinema. The Case of Miss Bala by Gerardo Naranjo.}

\begin{abstract}
Resumen
El presente artículo tiene por objetivo reflexionar en torno a la construcción de los imaginarios de la violencia desde el cine mexicano contemporáneo, sobre cómo se vinculan los imaginarios sociales con los imaginarios fílmicos. El pensamiento de Edgar Morin en torno a los imaginarios es crucial para dicha reflexión, partiendo también de algunas ideas de Merleau-Ponty sobre la fenomenología de la percepción. Para aterrizar el objetivo, se propone un ejercicio de análisis sobre Miss Bala (Gerardo Naranjo, 2011), cinta representativa que aborda el tema de la violencia que se acentuó a partir de la simbólica "declaración de guerra" al narcotráfico por parte del gobierno presidido por Felipe Calderón. Sus formas estéticas y narrativas permiten vislumbrar otro tipo de manifestaciones de violencia, que van más allá de la espectacularidad visual de la misma, para dejar entrever otras más intrínsecas y simbólicas, con base en la propuesta de Žižek. La presente reflexión puede proporcionar una perspectiva más panorámica sobre el papel que juegan el cine y sus imaginarios fílmicos en la constitución de los imaginarios sociales, sobre cómo se vive, se percibe, se condena y se asimila una realidad marcada por la narcoviolencia entre los mexicanos.
\end{abstract}

Palabras claves

Imaginarios, violencia, Miss Bala, cine mexicano.

\begin{abstract}
The article reflect on the construction of the imaginary of violence in the contemporary Mexican cinema, and how the social imaginaries are connected with the filmic imaginaries. Edgar Morin's suggestion about the imaginary is crucial for this reflection, also MerleauPonty's ideas about the Phenomenology of the perception. To support this aim, an analysis exercise of Miss Bala (Gerardo Naranjo, 2011) is proposed, a representative film that
\end{abstract}


approach the issue of violence that was increased since the symbolic "declaration of war" to drug trafficking during Felipe Calderón government. Its aesthetic and narrative forms allow the spectator to glimpse other manifestations of violence, which go beyond visual spectacular violence, to allow us to see more intrinsic and symbolic ways, based on the Žižek approach. The present reflection can provide the reader a panoramic perspective on the role played by the cinema and its filmic imaginaries in the constitution of the social imaginaries, on how one lives, perceives, condemns and assimilates a social reality pronounced by narco violence in Mexican society.

Keywords Imaginary, violence, Miss Bala, Mexican cinema.

En el México contemporáneo, la ola de violencia derivada del crimen organizado vinculado al narcotráfico ha sido un asunto crucial en la agenda política durante varios sexenios para el Estado. Ante esta situación, con la llegada de Felipe Calderón Hinojosa a la presidencia (2006-2012), se puso mayor énfasis en dicha problemática con la máxima de acabar de tajo con la narcoviolencia, sin cavilaciones ni negociaciones con los cárteles, para así "preservar la seguridad en los pueblos y ciudades y las familias mexicanas y que los hijos de éstas puedan crecer en un ambiente seguro y de prosperidad" (Calderón citado en Herrera y Aranda). Así pues, en diciembre del 2006, a unos cuantos días de haber entrado oficialmente a la presidencia, Calderón hace pública una declaración de guerra al narcotráfico, sin excepción o misericordia alguna. Esta declaración marcó una coyuntura política y social, pues se emprendió una lucha extenuante para cortar cabezas a mansalva de los capos más buscados. ${ }^{1}$

No obstante el empeño por confrontar al enemigo, con todo el apoyo de los cuerpos policiacos de todos los niveles (municipales, estatales, federales), así como los del Ejército y la Marina, los resultados no fueron alentadores y, por el contrario, han dejado un saldo inconmensurable de víctimas mortales e indirectas.

\footnotetext{
${ }^{1}$ La operación inaugural de esta campaña militar se llevó a cabo en el estado de Michoacán. Felipe Calderón envió cerca de 7 mil militares que se desplegaron en varias zonas del Estado, y se llevaron a cabo varias operaciones como la inspección de casi 18 mil personas y 8 mil 148 vehículos, la erradicación de 74 plantíos de mariguana en la zona costera y diversas embarcaciones nacionales y extranjeras. Datos recuperados de: http://www.jornada.unam.mx/2006/12/20/index.php?section=politica\&article=016n1pol 10 nov. 17.
} 
CATEDral TomadA: Revista de crítica literaria latinoamericana / Journal of Latin American Literary Criticism Imaginarios de la violencia en el cine mexicano contemporáneo. El caso de Miss Bala de Gerardo Naranjo.

Si bien, a lo largo de seis años de gobierno se detuvieron y se aniquilaron algunos líderes de cárteles del narcotráfico, no se logró el acometido de desarticular dichas organizaciones ni de irrumpir en sus estructuras financieras (Aristegui Noticias). Tanto periodistas como académicos y algunos funcionarios públicos coinciden en que el fenómeno de la violencia se acentuó mucho más a partir de las políticas de este gobierno. Se pasó de 8 mil 867 homicidios dolosos en 2007 a 27 mil 199 en 2011. A estas víctimas se le unen otros ciudadanos que han sufrido otro tipo de violencia, como vejaciones, torturas e incluso desaparición forzada (Comisión Mexicana de Defensa y Promoción de los Derechos Humanos 5). Asimismo, en el 2012, al término del mandato de Calderón, según datos del INEGI (Instituto Nacional de Estadística y Geografía), la población de 18 años y más, a nivel nacional, manifestaba como su principal preocupación, el tema de la inseguridad (57.5\%), seguido del desempleo (49.3\%) y la pobreza (34\%) (INEGI 2016).

La violencia, en cualquiera de sus modalidades (física, sexual, verbal, simbólica), siempre atañe a cuestiones éticas y, por ende, se vincula con los valores sociales construidos y resignificados en el devenir histórico. Para profundizar en la violencia como una herramienta de análisis resulta ilustrativa la propuesta del filósofo Slavoj Žižek. Por un lado, subraya la existencia de una violencia sistémica o estructural, que no es visible de forma directa y que es consecuencia generalmente del funcionamiento del sistema económico y político en que vivimos y somos normativizados (Žižek 10). Ésta, a su vez, se materializa en la cotidianeidad de los sujetos. A ésta, Žižek la llama violencia subjetiva, que es "directamente visible, practicada por un agente que podemos identificar al instante" (Žižek 9). Esta propuesta es pertinente al abordar el caso de violencia en México vinculado al crimen organizado en el marco del narcotráfico, pues las confrontaciones existentes entre este fenómeno y las estructuras gubernamentales -incluidos los cuerpos policiacos y militares- atienden a las leyes del mercado internacional, es decir, más allá de la ilegalidad de la industria de las drogas, ésta se mueve bajo las políticas neoliberales del capitalismo. 
La violencia sufrida, directa o indirectamente, ha generado una suerte de imaginarios colectivos que vinculan a los mexicanos desde cualquier punto geográfico del país. Los imaginarios de la violencia compartidos se condensan a través de elementos como el sentimiento o la sensación de una inseguridad ciudadana, que a su vez se ven reforzados por los medios de comunicación. Aunque la violencia tenga una base real, el imaginario se genera primordialmente a partir de medios discursivos, ya sean televisivos, fílmicos, de prensa escrita, en las redes sociales, etc. De acuerdo con Gerard Imbert, si se pretende aplicar una mirada transversal a estos escenarios de la realidad social, ésta "no puede eludir los contextos tanto pragmáticos como discursivos en que emerge el discurso de la violencia. Es más, los discursos sociales mediante su escenificación mass mediática instauran una cierta realidad que se ve a su vez reproducida" (Imbert, Escenarios 12). El impacto de la violencia mediatizada es tal que se asume como real, aún sin haber sido testigo directo de ella, tanto así que difícilmente podemos desvincular la violencia real de la violencia representada (19). Es en este difuso intersticio, entre lo real y lo representado, que un medio como el cine nos conduce a través de la imagen fílmica a un mundo que reactiva las percepciones y sensaciones del sujeto frente al mundo. En este sentido, si partimos de una reflexión fenomenológica, percepción e imagen son indisociables, pues "en todo acto perceptivo hay algo imaginado" (Aguilera 34). De tal modo que imagen y percepción se vuelven elementos esenciales para la comprensión de los imaginarios, por lo que consideramos pertinente la propuesta de la fenomenología de la percepción del filósofo francés Maurice Merleau-Ponty.

\section{De la percepción a los imaginarios}

Maurice Merleau-Ponty parte del concepto de "percepción”, dejando de lado el abstracto universal "yo pienso" y proponiendo una "fenomenología de la percepción" para la comprender las relaciones y los vínculos entre el sujeto y el 
CATEDRAL TOMADA: Revista de crítica literaria latinoamericana / Journal of Latin American Literary Criticism Imaginarios de la violencia en el cine mexicano contemporáneo. El caso de Miss Bala de Gerardo Naranjo.

mundo. Entiéndase en este contexto por fenomenología como "una filosofía que re-sitúa las esencias dentro de la existencia y no cree que pueda comprenderse al hombre y al mundo más que a partir de su "facticidad"' (Merleau-Ponty 7). Es decir, la percepción es la síntesis de la relación dialéctica entre sujeto (hombre) y objeto (mundo); éste último es en tanto que es percibido por el sujeto, y el sujeto percibe en tanto existe el objeto. El sujeto construye un campo perceptivo conformado por un sinfín de imágenes erigidas a partir de sensaciones, emociones e ideas que anteceden al Cogito. Como lo dice este pensador francés: "El mundo no es lo que yo pienso, sino lo que yo vivo; estoy abierto al mundo, comunico indudablemente con él, pero no lo poseo; es inagotable" (16). La reflexión filosófica desde el campo de lo fenomenológico rescata la unión entre el subjetivismo y el objetivismo, sin una jerarquización conceptual, mostrándose más bien en un plano de horizontalidad y de indisociabilidad.

El interés por el pensamiento merleaupontiano radica en que se aleja de la abstracción filosófica de carácter universalista, para centrarse en un pensamiento situacional, en un contexto histórico específico. La percepción se asocia al conjunto de experiencias que se tienen con los sentidos, sobre todo a las experiencias visuales a partir de las cuales construimos imágenes que sustentan la percepción desde la que el sujeto construye un prejuicio sobre el mundo (26-27). La relación dialéctica entre sujetos y objetos es crucial para la comprensión de las experiencias perceptivas. Por eso, los subjetivismos y los objetivismos ocupan un lugar relevante en la construcción de los imaginarios sociales y fílmicos.

Si bien, la aproximación hacia el cine por parte del autor francés referido fue escasa, resultan significativos algunos momentos alusivos a dicho tema, como la conferencia dictada en el IDHEC (Instituto de Altos Estudios Cinematográficos/ Institut des Hautes Études Cinématographiques), titulada "El cine y la nueva psicología" ("Le cinéma et la nouvelle psychologie"), dictada en 1945, en la que, según la lectura de Gilles Deleuze, aprovecha la ocasión para remitirse a la relación cine-fenomenología, en la que encuentra un área de oportunidad para comprender la percepción no de una forma inteligible 
(cognitiva-racional), sino de una forma sensible (Gestalt), "que organiza el campo perceptivo en función de una conciencia intencional en situación” (Deleuze 88). Para Deleuze, la alusión al cine por parte de Merleau-Ponty es un acto accesorio, pues lo hace para encontrar en el cine un aliado ambiguo (88). La ambigüedad radica, según Deleuze, en que la fenomenología confiere a la percepción natural un privilegio "que hace que el movimiento siga todavía vinculado a las poses (simplemente existenciales en lugar de esenciales); de ahí que se acuse al movimiento cinematográfico de ser infiel a las condiciones de la percepción, pero también que se lo exalte como un nuevo relato capaz de "acercarse" al o percibido y a lo percipiente, al mundo y a la percepción" (89).

Por su parte, el investigador Jorge Lucero sostiene que la aportación a la reflexión cinematográfica del filósofo francés es más significativa. Para Lucero, se ha mal entendido y demeritado el alcance de la reflexión de este autor en torno al tema de la percepción en el fenómeno cinematográfico. Además de la conferencia ya referida, Merleau-Ponty abordó el tema en otros escritos, como en El mundo sensible y el mundo de la expresión, notas del primer curso dictado en el Collège de France en 1953, en los que se logra vislumbrar un interés por situar al cine como un aliado de la ontología fenomenológica (Lucero 119). Para el pensador francés, un filme trasciende su condición tecnológica como representación del movimiento para devenir "una nueva manera de simbolizar el pensamiento, un movimiento de la representación" (Citado en Lucero 119).

De igual forma, el investigador Sergio Aguilera piensa que Deleuze no hace justicia al tratamiento sobre la imagen de parte de Merleau-Ponty. De acuerdo con la lectura de Aguilera, para el pensador francés la imagen "no es percepción debilitada, sino que comporta un elemento creativo que completa lo inacabo de la percepción. Ésta, producto del punto de vista proporcionado por el anclaje del cuerpo al mundo, se enriquece mediante la producción de imágenes" (34). En este sentido, las imágenes audiovisuales que nos proporciona el cinematógrafo plasman de modo más panorámico aquella percepción difusa o recortada del sujeto, de tal forma que lo imaginario se fortalece al vincularse con 
CATEDRAL TOMADA: Revista de crítica literaria latinoamericana / Journal of Latin American Literary Criticism Imaginarios de la violencia en el cine mexicano contemporáneo. El caso de Miss Bala de Gerardo Naranjo.

la construcción del imaginario fílmico, y éste a su vez se nos muestra como producto de un imaginario social por parte del realizador (y su equipo), ofreciéndonos un conjunto de formas de percepción sobre el mundo y sus circunstancias.

\section{Imaginarios sociales e imaginarios fílmicos}

El término "imaginario" suele vincularse coloquialmente con otros términos como "falso", "irreal", "ficticio", "mito", etc., términos que se utilizan de modo arbitrario y con tintes peyorativos frente a la cosmovisión de lo racional, frente al entendimiento de la razón. Se le asocia con mentalidades y ficciones, con estereotipos o prejuicios sociales que derivan de las subjetividades (Solares 130).

Todo imaginario es el resultado de una abstracción mental, un fenómeno de la psique, sin embargo, en este caso aludimos también al sentido social y cultural de este término, al asumir que los imaginarios atienden a un conjunto de imágenes simbólicas recreadas a partir de elementos y prácticas reales que son significadas y compartidas por un grupo de individuos en un contexto social y cultural determinado.

De acuerdo con el filósofo e historiador polaco Bronislaw Baczko, "las modalidades de imaginar, de reproducir y renovar el imaginario, como las de sentir, pensar, creer, varían de una sociedad a la otra, de una época a la otra y por consiguiente, tienen una historia" (27). Por lo que nos referimos a imaginarios como un conjunto de abstracciones mentales sobre ciertas imágenes, pero que tienen un trasfondo real y simbólico, no sólo en un sentido objetual, sino fenomenológico en el devenir histórico. En este sentido, la función del símbolo resulta crucial pues introduce valores y modela conductas individuales y colectivas. En palabras de Baczko: "todo símbolo está inscripto en una constelación de relaciones con otros símbolos; que las formas simbólicas que van desde lo religioso 
a lo mágico, desde lo económico a lo político, etcétera, forman un campo en donde se articulan las imágenes, las ideas y las acciones" (29).

La complejidad de lo imaginario nos remite a diversas lecturas desde varios campos disciplinares que construyen nociones y conceptualizaciones en función de sus propias metodologías y marcos teóricos. Por lo mismo, resulta una tarea difícil encontrar los puntos de convergencia para comprender de manera transversal las manifestaciones de los imaginarios sociales. En este sentido, algunos de los aspectos que consideramos significativos en las diversas nociones de lo imaginario son, por un lado, su constitución a partir de elementos emocionales y afectivos, así como elementos intelectuales y cognitivo condicionados por las circunstancias socioculturales. De acuerdo con Blanca Solares:

El imaginario designa una compleja procesualidad autónoma y dinámica de la intuición dando forma a las facultades sensibles y cognoscitivas. En virtud de su propia actividad, la imaginación in-forma, modela y reorienta a la razón, imagina sus posibilidades abriéndola allende de sus límites hacia inéditas territorialidades de la experiencia. (134)

La experiencia afectiva y cognitiva es indisociable, por lo que los sentidos juegan un papel central en la construcción de lo imaginario. Los sentidos nos permiten entrar en contacto directo con nuestro entorno, con el mundo, conocemos a través de los sentidos y abstraemos imágenes en nuestra psique generando así una experiencia senso-cognitiva. De tal modo que forjamos una serie de percepciones - en un sentido fenomenológico - sobre nuestro entorno y de nosotros mismos ante el mundo.

El "imaginario social" como una herramienta de análisis permite comprender de manera más dinámica las prácticas sociales y culturales de determinada sociedad de acuerdo a su espacio y tiempo, frente a las teorizaciones

\footnotetext{
${ }^{2}$ En este caso el uso de imaginario social o colectivo se hará de modo indistinto.
} 
CATEDRAL TOMADA: Revista de crítica literaria latinoamericana / Journal of Latin American Literary Criticism Imaginarios de la violencia en el cine mexicano contemporáneo. El caso de Miss Bala de Gerardo Naranjo.

formales sobre el orden moral de las sociedades. Mientras que las teorías sociales son construidas por minorías conformadas por intelectuales para explicar los fenómenos sociales, los imaginarios son mecanismos más democráticos e incluyentes. Para el filósofo canadiense Charles Taylor, pensar a través de los imaginarios permite extender la mirada hacia elementos cruciales de la cultura que forman parte de las identidades y memorias colectivas, como las imágenes, las historias, las leyendas, etc. (37). Por su parte, Gerard Imbert señala que posiblemente hoy día los imaginarios sustituyan a los modelos explicativos tradicionales de ideologías e identidades -homogéneas, lineales e inalterables-- en la conformación de lo social (Imbert, Cine e imaginarios 14-15).

En términos más formales, un imaginario es un "espacio" de encuentro, unidad o convergencia que se erige a partir de una serie de normas, valores, lenguaje, herramientas y métodos de caracteriza a una sociedad (Castoriadis 67). Para el filósofo Cornelius Castoriadis un imaginario consiste en una:

[....] urdimbre inmensamente compleja de significaciones que empapan, orientan y dirigen toda la vida de la sociedad considerada y a los individuos concretos que corporalmente la constituyen. Esa urdimbre es lo que yo llamo el magma ${ }^{3}$ de las significaciones imaginarias sociales que cobran cuerpo en la institución de la sociedad considerada y que, por así decirlo, la animan. [....] Llamo imaginarias a estas significaciones porque no corresponden a elementos "racionales" o "reales" y no quedan agotadas por referencia a dichos elementos, sino que están dadas por creación, y las llamo sociales porque sólo existen estando instituidas y

${ }^{3}$ Castoriadis entiende por magma un conjunto de significaciones imaginarias sociales propias de una sociedad dada, un tipo de organización que no es reductible a conjuntos o a sistemas de conjuntos, rechazando el funcionalismo y el estructuralismo para explicar estos conjuntos por sus principios de causalismo y finalismo. Para este autor, un magma no puede ser reconstituido analíticamente, por medio de categorías y de operaciones con conjuntos, negando así el determinismo (como el de la Física o las Matemáticas) usando un sentido histórico social (7273). 
siendo objeto de participación de un ente colectivo impersonal y anónimo. (68)

Jacques Le Goff, uno de los propulsores de la llamada Historia de las Mentalidades, insistía en que ésta se alimenta de los documentos del imaginario, sobre todo documentos literarios y artísticos, por sus formas de representación que nos trasladan a la mentalidad y la sensibilidad de una época (Le Goff 92-93). No obstante, el historiador francés advertía de la trampa de este tipo de documentos, pues los imaginarios literarios y artísticos no necesariamente nos hablan de facto de una conciencia colectiva, pues pueden obedecer a códigos más o menos independientes de su entorno espacio-temporal, por lo que señala que es imprescindible situar su análisis en sus lugares y medios de producción. Asimismo subraya la relevancia de los mass media como los vehículos y matrices privilegiadas de los imaginarios, que son "las nebulosas de donde se cristalizan las mentalidades" (Le Goff 94).

En este sentido, el cine, en tanto un medio de expresión artístico y un mass media, logra tener ese impacto en los imaginarios colectivos, pues como lo plantea Bronislaw Baczko, en este tipo de medios se lían relaciones muy complejas entre información e imaginación, ya que los "medios masivos de comunicación no sólo aumentan el flujo de información, sino que modelan también sus modalidades" (31).

En atención a lo anterior, el quehacer cinematográfico ha logrado atraer las miradas de las ciencias sociales (historia, antropología, sociología, psicología) cuyo afán en estudiar e interpretar desde sus respectivas trincheras los imaginarios fílmicos, se sostiene en la premisa de que estos reflejan por excelencia la proyección de los deseos y ensoñaciones del ser humano, así como las problemáticas sociales y culturales de cada sociedad en su historicidad. Tal como lo señala el antropólogo Francisco De la Peña Martínez: "Los imaginarios fílmicos están poblados de representaciones sociales y fantasmas colectivos que expresan los prejuicios, los deseos, los mitos, los miedos, las creencias y las 
CATEDRAL TOMADA: Revista de crítica literaria latinoamericana / Journal of Latin American Literary Criticism Imaginarios de la violencia en el cine mexicano contemporáneo. El caso de Miss Bala de Gerardo Naranjo.

utopías de las colectividades humanos, y todos ellos están anclados en el pasado histórico, la tradición cultural y la psique de los pueblos" (11).

El imaginario fílmico le da un cariz tangible a aquellas creencias que se asimilan como parte de la realidad social, de la cotidianeidad, pero que se quedan en un horizonte impreciso, con percepciones aparentemente inconexas. El imaginario fílmico le da nombre y figura a aquellas siluetas borrosas e indefinidas de sujetos y objetos del entorno, que se sabe que existen, que están ahí, a veces cerca, a veces lejos, pero que son parte del ambiente cotidiano. El cine construye realidades a partir de la ficción, de la invención y de la imaginación, en donde lo real y lo imaginario no se contraponen, sino que son indisociables. El cinematógrafo tiene esta cualidad ambivalente que nos remite a la realidad, al retrato fiel, al mismo tiempo que a la ficción, a la invención, a la ilusión; nos sumerge en mundos distópicos, utópicos, y quiméricos. El cinematógrafo, artefacto moderno que prometía alta fidelidad de la realidad, retrato enérgico del hombre y su entorno, derivó en un dispositivo creador de espectáculos ilusorios, irreales e increíbles que maravillaban a todo espectador. ${ }^{4}$

En este sentido, la objetividad y la subjetividad se entrecruzan irrestrictamente para recrear aquella magia que promete la pantalla cinematográfica. La imagen fílmica, con su cualidad que presume objetividad, en tanto reproduce "fielmente" secuencias fotográficas, atrapa al espectador para sumergirlo en otra realidad "real" -valga la redundancia--, pero percibida, experimentada e interiorizada de manera subjetiva. Es esto a lo que Morin llama el universo mágico del cine: “es la visión subjetiva que se cree real y objetiva. Recíprocamente, la visión subjetiva es la visión mágica en estado naciente, latente o atrofiado" (Morin 83). Una crea a la otra, y viceversa, digamos, en un sentido

\footnotetext{
${ }^{4}$ Edgar Morin profundiza en su obra El cine o el hombre imaginario esta cuestión ambivalente del cinematógrafo contraponiendo (dialécticamente) dos grandes ejemplos de la cinematografía: "Al realismo absoluto (Lumiére) responde el irrealismo absoluto (Meliés). Admirable antítesis que hubiera gustado a Hegel, de donde debía nacer y desarrollarse el cine, fusión del cinematógrafo Lumiére y de la Hechicería Melies" (Morin 52).
} 
dialéctico: "La realidad se enriquece con la imagen y la imagen con la realidad" (Morin 33).

Edgar Morin ha denominado a este fenómeno "proyección-identificación", el cual alude al proceso del sujeto espectador ante la imagen fílmica, cuya cualidad objetiva se deforma o trastoca por el contexto ideológico, cultural, anímico y emocional del que la experimenta (Morin 83). Es decir, como sujetos racionales estamos conscientes que como espectadores del cinematógrafo nos encontramos ante una "falsa" realidad que se desarrolla secuencialmente a través de fotogramas, no obstante, la afectividad que emerge en nosotros como espectadores nos hace traspasar esa difusa separación que hay entre la objetividad y la subjetividad. Somos conscientes de que estamos ante la proyección de un filme, pero éste nos atrapa y nos transfiere a su realidad por la capacidad que tiene de estimular nuestras percepciones emocionales, espirituales, sentimentales, etc. De este modo, caemos en cuenta que a lo que se refiere Morin con esta reflexión en torno a la objetividad-subjetividad y su complejo "proyección-identificación" tiene qué ver con la idea mundana de "eso podría ocurrirme" (Morin 149). Es el sujeto desplegando su "otro yo" (individual y colectivo) en el espejo de la pantalla cinematográfica, como una suerte de transferencia afectiva que va más allá de nuestra racionalidad y de la "objetualidad" del filme. El sentimiento de empatía y de identificación es clave para vivir esta experiencia estética.

La experiencia estética de cada espectador depende del conjunto de creencias y valores que posea, pues determinan desde la elección de un filme y las expectativas que puede tener de éste, así como el tipo de asociaciones que éste realiza con otras cintas, creando así una suerte de "inconsciente cinematográfico" (Zavala, Semiótica 231), o las interconexiones que hace entre su realidad social y la realidad fílmica. De acuerdo con Laura Zavala, la estética del cine se puede entender como un "conjunto de estrategias audiovisuales que provocan un efecto específico en la sensibilidad de los espectadores" (Versión 3). Por tanto, cuando hablamos de experiencia estética nos referimos al conjunto de sensaciones, pensamientos y emociones generadas a partir de un imaginario fílmico. 
CATEDRAL TOMADA: Revista de crítica literaria latinoamericana / Journal of Latin American Literary Criticism Imaginarios de la violencia en el cine mexicano contemporáneo. El caso de Miss Bala de Gerardo Naranjo.

Sobre la cuestión estética, Morin sostiene lo siguiente: "Lo imaginario estético, como todo lo imaginario, es el reino de las necesidades y aspiraciones del hombre, encarnadas y puestas en situación en el marco de una ficción. Se nutre en las fuentes más profundas e intensas de la participación afectiva” (92). Lo imaginario estético del que habla Morin es una idea central, pues es la articulación clave para dialogar entre los imaginarios sociales y fílmicos. Lo estético entendido como el modo en que se crea una obra con el fin de conmover o afectar al espectador. Lo imaginario entendido como la forma en que esa serie de sensaciones y afectaciones se vinculan con nuestro entorno, con nuestras necesidades y deseos, a nivel individual y a nivel colectivo.

Así pues, los imaginarios fílmicos, permeados de realidad, pero también de fantasías y de ficción, son indisociables de los imaginarios sociales. Es decir, los imaginarios fílmicos construidos en cualquier cinta parten de un referente social, no sólo por la reproducción de los sujetos, objetos y espacios reales de determinado lugar, sino por los referentes situacionales de cada una de ellas en función del entorno social. Es cierto que las imágenes en sí no son reales (tangibles), pero son un analogon perfecto de la realidad (Barthes 13), por lo que el cine se fundamenta en un cimiento analógico por su naturaleza de reproducción fotográfica. Sin embargo, su capacidad de reproducir la realidad no lo libra de cargar con mensajes con significados específicos y subjetivos.

\section{Imaginarios de la violencia: Miss Bala como un filme paradigmático}

Aquellas imágenes disociadas y fragmentarias en la mente de todo individuo cobran vida cuando son hilvanadas visual y sonoramente a través de la pantalla cinematográfica. Retazos de la memoria sobre la violencia quedan rezagados en el imaginario colectivo de los individuos que se familiarizan con este infortunio. Recuerdos, sensaciones, ideas, creencias generados a partir de lo vivido, lo visto, lo leído, lo escuchado, lo platicado sobre las desventuras de la 
narcoviolencia toman un cariz determinante cuando es visto a través del cinematógrafo. Todas estas imaginerías cobran sentido cuando se entretejen a través de una narrativa fílmica, pues una serie de imágenes que son puestas en movimiento se configuran espacial y temporalmente a través de recursos técnicos y artísticos que van desde el uso de distintos planos y movimientos de cámara, así como de decoración, iluminación, sonidos, etc., que en su conjunto es conocido como montaje (Morin 57).

De tal forma que lo que se cree que sucede alrededor se torna real a partir de la ficción. En pocas palabras, el cine es realidad y ficción al mismo tiempo, de ahí su magia y su complejidad. El cine es realidad incluso de forma involuntaria, pues sus construcciones ficcionales siempre tienen un valor etnográfico, un alcance antropológico (De la Peña 23) que hacen referencia a las problemáticas sociales, las prácticas culturales, las ideologías, los mitos y la memoria colectiva de algún grupo social o comunidad determinada.

Cuando hablamos de los imaginarios de la violencia, nos centramos en el asunto de cómo se percibe la violencia social, a partir de qué elementos o referentes y de cómo se hilvanan dichos elementos de tal forma que existe cierta empatía, un sentir de angustia e inseguridad entre los ciudadanos a raíz de los actos violentos que se han acentuado. ${ }^{5}$ Sin tener la intención de demeritar esta realidad, el interés radica más bien en cómo se percibe esta violencia en los imaginarios colectivos, y sobre todo, cómo contrastan o se refuerzan a partir de los imaginarios fílmicos que hacen alusión al tema.

En este caso, hemos elegido la película Miss Bala (Gerardo Naranjo, 2011), una historia que está inspirada en el caso real de la ex reina de belleza Laura Zúñiga, quien ganó el certamen Miss Sinaloa edición 2008. Más tarde se le vinculó con Ángel Orlando García Urquiza, operador del cártel de Juárez,

5 Resulta interesante este punto, pues las instituciones públicas han mostrado interés y preocupación por la percepción de la ciudadanía sobre temas como la seguridad pública, la corrupción y la impartición de justicia. Un claro ejemplo es el conjunto de proyectos que lleva a cabo desde 2011 el INEGI los cuales incluyen en sus muestreos estadísticos encuestas realizadas a ciudadanos sobre estos temas. Véase: http://www.beta.inegi.org.mx/temas/percepcion/ 17 agosto 2017. 
CATEDRAL TOMADA: Revista de crítica literaria latinoamericana / Journal of Latin American Literary Criticism Imaginarios de la violencia en el cine mexicano contemporáneo. El caso de Miss Bala de Gerardo Naranjo.

también identificado por la PGR (Procuraduría General de la República) como "uno de los pesados de Navolato", tierra de los líderes de esa organización: Vicente Carrillo Fuentes y Vicente Carrillo Leyva (Castillo y Valdez). Después de unos meses y tras haber estado algunos días bajo arraigo, fue puesta en libertad sin habérsele comprobado delito alguno. Las relaciones entre algunas "misses" y miembros de diversos cárteles que se han dado a conocer a través de los medios no han sido pocos, ni privativos de México; lo cierto es que en su mayoría ignoramos cómo se configuran estas relaciones sentimentales y de poder. En esta cinta, Naranjo no pretende discutir dicho punto, sino reconstruir, a partir del caso de Laura Zúñiga, un posible (o posibles) escenario(s) de las víctimas del narcotráfico, haciendo una denuncia de lo que ha pasado en los últimos años, a partir de esta declaración de guerra.

En entrevista con el periódico La Jornada el director comentó lo siguiente: "hablamos de un tema que nos duele. Tomamos la decisión de hacer una película que, lejos de proponer soluciones, da un punto de vista del fenómeno que estamos viviendo, que creemos que no se ha dado; quisimos adentrarnos y verlo desde la visión de un ciudadano normal" (Caballero). Por otra parte, en una revista cultural, Naranjo sustenta que en su filme no se verá ninguna tortura, más que los recursos de violencia necesarios para que sea verosímil la trama, sino más bien recrear "un acto patético" (Ventana Latina). La intención es mostrar el miedo, comenta Naranjo, "pero ese miedo generado por la falta de comunicación entre la sociedad, entre la gente" (Ventana Latina). Por lo que la sensación de miedo que impera en los ciudadanos mexicanos se vuelve parte de esta percepción de inseguridad por la violencia, es el miedo el que compartimos a través de los imaginarios.

La trama gira en torno al personaje de Laura Guerrero, una joven de 23 años de edad, quien vive con su padre y hermano menor en las periferias de Tijuana, ciudad ubicada al norte del estado de Baja California y limítrofe con la frontera de Estados Unidos. Laura y su amiga Zuzú (Azucena Ramos) comparten el sueño de ganar el concurso de Belleza "Miss Baja", sin embargo, su amiga se 
relaciona con un miembro que al parecer está vinculado al crimen organizado. Cuando su amiga desaparece, tras una balacera desatada en un antro, Laura ingenuamente acude a la policía para que la ayuden a buscarla, pero ésta resulta estar vinculada con otros grupos delictivos. A partir de este momento, Laura se ve envuelta en una serie de desencuentros vinculados a los negocios de Lino, líder del grupo, usada como mula, como objeto sexual y carne de cañón.

$\mathrm{Su}$ impacto en taquilla de las salas comerciales fue sobriamente exitoso. De acuerdo con los datos del Anuario Estadístico de Cine Mexicano 2011, Miss Bala destaca en el Top Ten de películas nacionales exhibidas en este año, proyectándose en 104 pantallas del país, con 100 copias, con 405 mil entradas y recaudando aproximadamente 1 millón 500 mil pesos (IMCINE, Anuario Estadístico de Cine Mexicano 2011). Es una cinta realizada en coproducción con Estados Unidos, bajo la productora Canana Films y distribuida por FOX Internacional Productions. Asimismo, recibió estímulos por parte del Instituto Mexicano de Cinematografía a través de FIDECINE y Promecap (Filmaffinity). Si bien, la película no aparece en el Top Ten general, pues en éste predominan producciones estadunidenses, los datos anteriores nos muestran que su éxito fue significativo, además de que su proceso de producción, distribución y exhibición fue operado por organismos acaudalados del gremio.

El recibimiento de la película por la crítica fue grosso modo buena, con halagos a la forma artística en que aborda el tema de la violencia, así como por su contenido social, aunque no faltaron quienes opinaron que ésta se acumula al montón de cintas relacionadas con el tan desgastado tema de la narcoviolencia. Tras su lanzamiento en el Festival de Cannes edición 2011, Miss Bala ha sido aclamada por la crítica. Fue nominada a varios premios Ariel, y reconocida en varios festivales internacionales, como el de Palm Springs, Filadelfia y San Sebastián. La página web Rotten Tomatoes reporta una aprobación del 90\% y en Metacritic, recibió una puntuación media de 82. 
CATEDRAL TOMADA: Revista de crítica literaria latinoamericana / Journal of Latin American Literary Criticism

Imaginarios de la violencia en el cine mexicano contemporáneo. El caso de Miss Bala de Gerardo Naranjo.

\section{De la imaginación a la representación de la violencia ${ }^{6}$}

Lo que hace singular a esta cinta son las formas -estéticas y narrativas- en que se recrea esta violencia. Por un lado, destaca la intención de alejar a los protagonistas de las tipologías gastadas de otras producciones (fílmicas y televisivas) que abordan el tema de la narcocultura, ${ }^{7}$ del narcotraficante grotesco, mal hablado, con ropas extravagantes y alhajas de oro, así como de las "misses" arribistas que se vinculan con narcotraficantes para adquirir dinero y poder. Son personajes con un perfil psicológico difícil de desentrañar, pues no hay pistas suficientes, por lo que el narcotraficante podría ser cualquier hombre ordinario, así como la joven aspirante a reina de belleza, podría ser cualquier chica común. En esta historia los dilemas morales no tienen cabida, pues las circunstancias adversas por las que atraviesa el personaje de Laura superan la posibilidad de decidir sobre sus actos. Al respecto, el realizador comenta lo siguiente:

La "narcocultura" está tratada en las películas de forma muy banal, casi como si fuera una comedia. Por no hablar de las telenovelas melodramáticas que son capaces de insultar la sensibilidad de uno a la hora de abordar un tema tan terrible. Creía necesario acercarme de una forma más real, tratar [de] viviseccionar la violencia que generan los narcos y sus acciones. Fue en el proceso de investigación que descubrimos que todo era mucho más triste de lo que pensábamos, todo era muy patético. De ahí que quisiéramos hacer una película que no justificara la mente de los criminales, sino tratar de verlo desde alguien que sufre dicha violencia. (Calvo)

${ }^{6}$ Agradezco los comentarios realizados por el Dr. Josetxo Cerdán Los Arcos, profesor del Departamento Periodismo y Comunicación Audiovisual, de la Universidad Carlos III de Madrid.

${ }^{7}$ Me refiero a este concepto como un conjunto de rasgos que caracterizan la vida de los narcotraficantes y sus acciones, y cómo a partir de estos rasgos se generan estereotipos que permean el imaginario colectivo de la sociedad en relación con el fenómeno del narcotráfico. Para profundizar en este término véase: Fernando Bustos Gorozpe, "Narco Cultura, el documental", Nexos, 4 abril, 2014. cultura.nexos.com.mx/?p=6209 [Consulta: 27 noviembre 2017]. 
Otra peculiaridad es la escasa presencia de diálogos, estos son parcos y a veces monosilábicos, además prevalecen los planos secuencia largos y pausados, lo cual puede resultar fastidioso para el espectador apasionado del cine de acción, o de los thrillers con sonidos estrepitosos, además de carecer de música extra diegética. En palabras del director: "siento que los diálogos de explicación de lo que estás haciendo es solo ruido para el verdadero idioma del cine, que es experimentar sensorialmente algo que tú ya has vivido y con lo que te puedes conectar" (Ventana Latina). Con esta afirmación, el realizador enfatiza las cuestiones sensoriales frente al lenguaje hablado, que resulta un proceso de raciocinio; las emociones y sensaciones llegan directa y espontáneamente al espectador, la experiencia estética se logra a través de estos recursos narrativos y visuales.

En este sentido, si la estética cinematográfica es un conjunto de herramientas audiovisuales cuyo objetivo es generar en el espectador una vivencia llena de emociones y sensaciones, una estética de la violencia debe reunir una serie de estrategias audiovisuales que provoquen un efecto específico en la sensibilidad de los espectadores al construir mecanismos de representación de la violencia y que puede ser ambivalente el efecto que ésta cause en ellos; puede llevar a una actitud crítica o de rechazo, dependiendo de múltiples factores sociales (Zavala, Versión 3). Las formas y los mecanismos usados por el director y su equipo técnico y artístico para representar la violencia son claves para lograr una estética de la violencia que conmueva o perturbe al espectador de diversos modos.

Naranjo ha comentado que uno de sus propósito era evitar mostrar imágenes con impacto visual muy violento -sangre, cabezas rodando, cuerpos destazados--, bajo el argumento de que se puede representar una historia de violencia sin mostrarla tal cual. No obstante, consideramos que existen manifestaciones de violencia representadas de otras maneras. El director utiliza ciertos recursos estéticos de tal forma de que la violencia se perciba, se olfatee, se intuya, aún sin mostrar imágenes espectaculares de violencia. Es a través del 
CATEDRAL TOMADA: Revista de crítica literaria latinoamericana / Journal of Latin American Literary Criticism Imaginarios de la violencia en el cine mexicano contemporáneo. El caso de Miss Bala de Gerardo Naranjo.

personaje de Laura que podemos recorrer y sentir distintos momentos de violencia, pues su cuerpo se convierte en recipiente y también proyector de aquellas expresiones de violencia no-vistas. Para aterrizar esta reflexión se han elegido algunas secuencias que considero significativas en torno al tema abordado.

En la primera escena podemos deducir ciertas características del personaje de Laura y su entorno. En un primero momento, a través de un plano fijo de larga duración, se muestra su habitación con varios recortes de revistas y afiches que exponen a artistas, como Madonna y Mariah Carey, modelos y reinas de belleza, con cuerpos seductores y poca ropa. Entre todos esos recortes se puede apreciar una que otra fotografía en donde se intuye que en una está Laura con su madre (ausente en la trama) y otra en donde aparece abrazada con su amiga Zuzú, con quien decide inscribirse en el concurso de belleza. Esto permite entrever que se trata de una joven con aspiraciones y deseos de ser parte de esta farándula, de pertenecer al mundo de la alta moda y conseguir fama y dinero. Posteriormente, en otro encuadre se puede apreciar la casa en la que vive Laura con su hermano menor y su padre. A través de unos cuantos diálogos se sabe que su padre se dedica a vender ropa en un tianguis o mercado y que viven en una casa humilde y modesta, en las periferias de la ciudad (Tijuana). Además, en esta escena Laura le hace saber a su padre que irá a inscribirse al concurso de belleza, quien no se ve muy convencido sobre esta idea.

Posteriormente, en otro encuadre, aparece Laura de espaldas, en un primer plano y un fondo con vista a la playa, la costa de la ciudad de Tijuana. Mientras tanto, aparece el título de la película "Miss Bala" en letras rojas, el cual podríamos interpretarlo como un juego de palabras en donde la palabra "Bala" hace, por un lado, referencia al contexto de la película, pues se ve involucrada en una serie de situaciones de violencia, como confrontaciones con armas entre grupos delictivos adversos y, por otro lado, bien puede representar la noción del concurso de belleza "Miss Baja", que hace alusión al certamen en el marco del estado de Baja California. Sin certezas, podríamos sugerir que se trata de un 
tropos que simula un doble mensaje partir de un juego del lenguaje escrito, pero también visual, pues las letras, que son color rojo carmesí también podrían hacer alusión a la sangre derramada por las balas. A través del título, también se puede sugerir una universalización, pues "Bala" se apropia de cualquier espacio geográfico (por lo menos de México), haciendo alusión a que este símbolo de violencia puede aplicar en cualquier espacio.

A continuación cuando se presentan Zuzú y Laura a la convocatoria del concurso de belleza, a través de un plano secuencia de varios segundos de duración la cámara nos muestra en un plano americano (de la cintura para arriba) toda una fila de mujeres que desean inscribirse al certamen. La cámara nos narra de cierta forma cómo cada una de estas mujeres interesadas en el mundo de la moda y de la belleza pueden ser próximas presas del narcotráfico. A su vez, podríamos plantear el retrato de un conjunto de mujeres, presas de una violencia estructural, de género, en la que está inscrita la práctica cultural de sexualizar y objetivizar el cuerpo femenino, pues los criterios de selección para estos certámenes son delimitados en función de los estándares de belleza occidentales o exotizados (delgadez, estatura alta, piel clara, o bien, tez bronceada, como la de Laura). La estética de la vestimenta de estas mujeres, vestidos diminutos con escotes pronunciados y estampados estrafalarios, insinúa también los estándares para lucir atractiva al espectador.

Laura y Zuzú acaban de pasar la primera prueba para el certamen. Pero la relación amorosa que mantiene Zuzú con un policía angustia a Laura. En una de las siguientes secuencias, Laura va a buscar a Zuzú a un antro en donde están miembros de grupos delictivos e intenta advertirle sobre la confrontación que se desatará. Mientras Laura está en el baño, se percata de que un grupo de hombres armados irrumpirá en el lugar, por lo que Laura se refugia debajo de los lavabos. $\mathrm{Su}$ rostro denota temor y angustia. Uno de los hombres (Lino) se acerca a ella, no se muestra su rostro, la cámara realiza un close up al arma que porta y posteriormente recorre sus piernas y sus pies, que calzan unas botas de casquillo. El sujeto le pregunta por los presentes en el lugar y a pesar de no darle una 
CATEDRAL TOMADA: Revista de crítica literaria latinoamericana / Journal of Latin American Literary Criticism Imaginarios de la violencia en el cine mexicano contemporáneo. El caso de Miss Bala de Gerardo Naranjo.

respuesta, le avienta un par de billetes y le pide que se vaya. En términos simbólicos, la escena muestra una disimetría entre Laura y el hombre: él mirando hacia abajo, ella hacia arriba. El sometimiento es claro, la relación de dominación también lo es, elementos como el arma y el dinero acentúan esta asimetría entre los sujetos.

Tras la orden del sujeto, Laura corre en el intento de avisarle anticipadamente a su amiga Zuzú. La cámara queda fija en la bolsa de plástico en la que cargaba su vestido con el que realizó su primera prueba para el certamen de belleza. La contemplación de este objeto nos invita a pensar en que es justo ese instante en que abandona su sueño, en el que pierde el control y la voluntad sobre su ser, sobre su cuerpo, pues a partir de ese momento vendrán las desventuras para Laura. Preocupada por su amiga Zuzú, pasa la noche en vela fuera de su casa esperando alguna noticia. Al día siguiente decide pedir ayuda a un policía de tránsito para su búsqueda. Éste le dice que la llevará a la comandancia para que levanten un reporte, pero en realidad la entrega al grupo de hombres que un día antes atacó el antro. Debido a esto, Laura se verá envuelta en una serie de desencuentros vinculados a los negocios de Lino, líder del grupo, usada como mula, como objeto sexual y carne de cañón. De un día para otro su vida da un vuelco de 360 grados, aunque irónicamente es coronada como "Miss Baja" California.

\section{Violencia "fuera de cuadro", una invitación a la imaginación}

Si algo ha llamado la atención de la película de Naranjo es su forma tan perspicaz de "mostrar" la violencia sin mostrarla. Es decir, que usando ciertos recursos técnicos (encuadres, planos, ángulos, iluminación, sonidos), se las ingenió para no mostrar de modo literal escenarios tan obvios sobre las secuencias de violencia. El director frecuentemente hace uso del "fuera de cuadro" como una 
especie de figura retórica de omisión, en donde la imagen visual se vuelve más bien una sugerencia de lo que está pasando.

En la escena en que Laura trata de advertirle a su amiga Zuzú de que pronto se desatará un enfrentamiento en el antro, justo en ese momento empiezan a dispararse las armas, las luces se apagan y Laura se tira al piso. La cámara la sigue al ras del suelo, con una iluminación casi nula podemos apreciar vagamente algunos artilugios como mesas y sillas tiradas, envases de botella rotos, entre otras cosas. Lo que alcanza a resaltar es un cuerpo tirado a un costado de Laura que porta una chamarra con el impreso de las iniciales de la DEA. El contraste del color blanco del impreso frente a la lobreguez de la escena hace que no pase como algo desapercibido, por lo que nos sugiere algo más que un cuerpo caído. De tal modo, esta forma de representar un evento violento se subvierte al jugar con la poca iluminación. La escena se torna más violenta por la imagen sonora, pues de fondo se escucha la estrepitosa canción de "El sonidito" (interpretada por el grupo Hechiceros Band) a manera de música incidental, como una antesala de los ruidos estridentes de las armas disparadas

Los primeros planos enfocados hacia el rostro de Laura son frecuentes. Estos funcionan, por un lado para denotar las emociones y sensaciones al límite por las que atraviesa constantemente y, por el otro, para evitar la obviedad de las escenas de acción en donde abundan las armas, los balazos, la sangre, cuerpos caídos, etc. Esto no quiere decir que estos estén ausentes, simplemente se retratan a manera de fondo o como elementos secundarios, pues la atención nos lleva más al rostro y al cuerpo de la protagonista, a experimentar la violencia a través de sus ojos y sus sentidos, de lo que ve y lo que percibe. Lo que no queda la vista, se nos deja a la imaginación, nos invita a suponer, a conjeturar en función de nuestros referentes de la violencia que nos es familiar.

En la escena en que Laura es aprehendida por los secuaces de Lino, es transportada en una camioneta, mientras tanto la constriñen físicamente para sacarle información. A través de un plano picado, observamos la cabeza y parte de su torso en el encuadre mientras dos hombres la forcejean con sus brazos. Este 
CATEDRAL TOMADA: Revista de crítica literaria latinoamericana / Journal of Latin American Literary Criticism Imaginarios de la violencia en el cine mexicano contemporáneo. El caso de Miss Bala de Gerardo Naranjo.

ángulo nos remite a la vulnerabilidad de la protagonista, con dos cuerpos que la someten, que denotan la inferioridad en la que se encuentra ahora frente al poder legitimado por la violencia física que tiene que sobrellevar a partir de este momento. En la siguiente escena, cuando Laura es conducida con el jefe, es decir, Lino, podemos apreciar a Laura en primer plano, con la mirada cabizbaja y el gimoteo del llanto, el temor se apodera de ella. Mientras tanto, al fondo observamos a Lino, acechándola con la mirada.

En la secuencia en que Laura, tras cruzar la frontera con Estados Unidos para dejar un encargo de Lino, se topa con una balacera, vemos a Laura en primer plano, en donde revela la zozobra y el miedo que siente por lo que está pasando a su alrededor, lo que está fuera de cuadro. Refugiándose lo más que puede al interior del vehículo, Laura se confronta muy cercanamente a la muerte, pues son incontables las balas impactadas en los vidrios de la camioneta. De tal modo que de nuevo las imágenes sonoras se apoderan de la puesta en escena de violencia, nos remiten a todos esos cuerpos caídos, a la sangre derramada. Así contemplamos a Laura durante varios segundos, hasta que llega uno de los secuaces y la extrae del vehículo para resguardarse en otro sitio. En el trayecto se vislumbran algunos cuerpos abatidos y charcos de sangre, vemos el impacto de las balas en los autos y en los cuerpos. Laura nos conduce de modo parcial por este terrorífico panorama. Posteriormente, en el camión de carga, a través de un plano secuencia de $360^{\circ}$, la cámara recorre los rostros anónimos de estos hombres que entrañan misterio, en medio de un silencio que se percibe aún más ensordecedor que el ruido de los disparos. Son sujetos ordinarios que cometen actos de horror, no representan al prototipo de héroe o antihéroe. Son victimarios y a la vez víctimas de la violencia sistémica, como lo señala Žižek.

En la escena en que Laura está en la habitación del hotel con el general y éste cae en cuenta que habrá un enfrenamiento, le demanda a Laura que se quede quieta en la cama. Después entra un hombre armado que se tiende en la cama a un lado de Laura. Los dos rostros frente a frente, las miradas comparten la desazón imaginando lo venidero, el hombre tiembla sudoroso de miedo mientras sostiene 
una ametralladora. Cuando la balacera se desata, Laura alcanza a resguardarse debajo de la cama. Mientras tanto, somos testigos de una confrontación a muerte. Armas que se disparan continuamente, varios hombres asesinados a mansalva podemos imaginar, pero sólo vemos uno que cae al piso justo frente a los ojos de Laura, al fondo se vislumbran otros dos militares caídos. La cámara nos ofrece esta mirada en un plano subjetivo, quedando únicamente el espectro que abarca la mirada de Laura. De pronto aparecen dentro de cuadro las piernas de Lino, quien se acerca al cuerpo inerte y al revisar si sigue con vida o no, descubre el escondite de Laura, su mirada sigue siendo acechadora.

Tras estos ejemplos explorados, podemos distinguir recursos técnicos y estéticos en Miss Bala que de manera singular recrean escenarios de violencia. Se trata de una violencia no espectacularizada, por lo menos dentro de cuadro. En los tres enfrentamientos en que se ve inmiscuida Laura, la cámara se inclina por poner atención al personaje en cuestión, dejando en un plano secundario -si lo leemos de manera literal — toda la parafernalia de las balaceras. Al respecto, Gerardo Naranjo sostiene que desde el inicio tenía claro que no quería convertir su historia en una trama de acción que destacara por la cantidad de muertos y de sangre derramada, sino más bien intentar subvertirla:

Había una pretensión formal muy marcada ya desde el principio. Queríamos subvertir el género, estábamos haciendo un thriller donde jamás se conocería la mente del protagonista: no sé si llamarlo un antithriller o un thriller intimista. Nos comprometimos con la ignorancia de ella, decidimos saltarnos los códigos de las secuencias de acción. No queríamos filmar la gloria de la batalla sino el patetismo de los objetos cayendo. Filmábamos los resultados, no las acciones. Como en la secuencia del accidente rodada desde el interior del coche. No creo que sea necesario mostrar al monstruo para asustar, basta con que la gente le pueda ver el pie. Es un lenguaje off que espero que la gente pueda disfrutar. (Calvo) 
CATEDRAL TOMADA: Revista de crítica literaria latinoamericana / Journal of Latin American Literary Criticism Imaginarios de la violencia en el cine mexicano contemporáneo. El caso de Miss Bala de Gerardo Naranjo.

De tal modo, las estrategias de representar la violencia vía la imagen fílmica incitan, más que a la literalidad, a la sugerencia, a la imaginación por parte del espectador, a completar la imagen de la violencia representada en el filme con los fragmentos latentes en la memoria y en el recuerdo que han forjado un imaginario colectivo de la violencia, y en este caso, de la narcoviolencia. Porque esta violencia lleva de antemano la insignia del "narco" que va más allá de la producción y tráfico de narcóticos. En los fenómenos desatados de esta violencia encontramos una serie de símbolos que nos transportan a espacios vividos e imaginados en común. No hace falta mostrar de modo preciso los escenarios de la violencia, pues aquellos elementos simbólicos retratados no sólo invisten un objeto en sí, sino también las reacciones del sujeto frente a ese objeto observado.

\section{De la estética a la ética de la violencia}

Estas formas estéticas de la violencia trascienden el discurso fílmico y revelan aquella violencia sistémica o estructural y subjetiva que Žižek ha señalado, siendo el trasfondo del narcotráfico el que la delata. La violencia subjetiva se materializa en la relación de víctima (Laura) y victimario (Lino). El cuerpo de Laura se convierte en un contenedor de significaciones simbólicas y semióticas; a través de su cuerpo comprendemos y percibimos el dolor, el sufrimiento, la humillación y el horror de la narcoviolencia. Los close up a su rostro, los primeros planos de su cuerpo desvelan la violencia que está fuera de cuadro. Los imaginarios fílmicos se vinculan insoslayablemente con los imaginarios colectivos, con una realidad social compartida. Estos cuerpos son resignificados en su contexto a través de normas sociales y políticas, pues de acuerdo con Judith Butler: 
[...] ser un cuerpo es estar expuesto a un modelado y a una forma de carácter social, y eso es lo que hace que la ontología del cuerpo sea una ontología social. En otras palabras, que el cuerpo está expuesto a fuerzas sociales y políticamente articuladas, así como a ciertas exigencias de sociabilidad -entre ellas el lenguaje, el trabajo y el deseo- que hacen posible el persistir y prosperar del cuerpo. (15-16)

La violencia que padece Laura a lo largo de la trama es mostrada en diferentes facetas. Podríamos hablar de una violencia simbólica relacionada con los formatos de concursos de belleza, los cuales condicionan los parámetros físicos y sexuales que debe cumplir un buen perfil. Esto es un claro ejemplo de mercadería de cuerpos en las dinámicas de la violencia sistémica, estructural e institucional, pues las relaciones de poder están en juego. Laura se resignifica constantemente en función de su cuerpo: como concursante de belleza, como mula para transportar fajos de billetes a Estados Unidos, como objeto de violación sexual, como informante para la DEA, Laura al servicio sexual de los cuerpos militares, así como a la policía judicial, para después ser botada en la calle, justo frente a unas bodegas que parecen ser usadas para la maquila. La trama cierra con esta representación, y se muestra como un guiño por parte del director que podría interpretarse como parte del círculo vicioso de la violencia: Laura es "liberada", pero su futuro seguramente se encontrará en estos espacios, donde su persona, su cuerpo seguirá siendo explotado económicamente y muy posiblemente violentado física y moralmente. Este plano final amplía el círculo de la violencia al del mundo del trabajador, determinado por la vulnerabilidad a raíz de su condición económica-laboral y de género.

La violencia sexual que pesa en el cuerpo de Laura se entrecruza con su condición de género y socioeconómica. En la violencia no hay igualdad, pues "allí donde ésta se manifiesta hay necesariamente alguien que la ejerce y alguien que la padece” (González 241). Tal vez, la escena más explícita sea la que retrata el acto sexual al que se ve forzada Laura por parte de Lino. En medio de la penumbra y 
CATEDRAL TomadA: Revista de crítica literaria latinoamericana / Journal of Latin American Literary Criticism Imaginarios de la violencia en el cine mexicano contemporáneo. El caso de Miss Bala de Gerardo Naranjo.

desolación de una playa, Lino le pide que se desnude y así sin más, lleva el acto de violación. Laura, con una actitud desesperanzadora, jamás pone resistencia. Tal vez, Laura, asustada de lo que pudiese acontecer en medio de la oscuridad y, por ende, de la incertidumbre frente a un futuro próximo, opta-desesperanzada-- por algo que le es más imaginable: la violación. Porque su cuerpo ya está marcado intrínsecamente como un cuerpo violentado en potencia. En este sentido, vemos la violencia de modo dialéctico, "la cual se articula sobre dos posiciones prefiguradas a partir de una doble oposición: entre lo activo y lo pasivo, entre el sujeto y el objeto. El hombre representa la posición activa, la del sujeto del acto. A su vez, la mujer representa la posición pasiva, la del objeto del acto" (González 242). Sin importar el acto de violencia llevado a cabo, éste es incompatible con la igualdad, pues ahí donde se manifiesta se muestra su abismal diferencia imposible de ser ignorada ( 241).

Es a través de Laura que hay continuidad en esta serie de confrontaciones violentas, es a través de sus gestualidades que percibimos el horror de aquellas escenas parcialmente "invisibles", del miedo causado en la víctima. El cuerpo de Laura nos conduce por la vereda de la narcoviolencia, disfrazada, maquillada $u$ ocultada del encuadre, para no hacer evidente lo ya evidente, para centrarnos en el miedo y terror en y a través del cuerpo de Laura, como víctima, pero también como espectadora de esa violencia. A través de ella podemos imaginar y sentir los temores e incertidumbres que padece; se trata de un personaje al límite constante, siempre a la deriva y próxima a la muerte. Si bien no se revelan de manera directa o panorámica los hallazgos de violencia, el sonido prevalece sobre lo visual, los ruidos estrepitosos de las armas o el impacto de las balas son suficientes para causar consternación, angustia o sobresalto en el espectador. A su vez, lo no visto, lo que hay fuera de cuadro invita a imaginar un panorama tétrico y desgarrador; este tipo de encuadres que crean tal tensión entre los diferentes elementos, tanto dentro como fuera de cuadro, lo cual logra recrear un entorno de desasosiego para el espectador. 
Así pues, asumimos que el cuerpo es ontología biológica y social de los sujetos. El cuerpo es el vehículo mediante el cual el ser humano vive, experimenta, percibe y aprehende el mundo en función de sus circunstancias. Como sujetos inmersos en un constructo cultural asumimos ciertos roles condicionados por los códigos sociales y morales dentro de una sociedad determinada. En este caso, las relaciones de sexualidad, entendiendo éstas como una construcción sociohistórica, producen cuerpos sexuados, femeninos y masculinos, productos de una cultura (Fagetti 15). En este sentido, como lo ha propuesto Foucault, la anatomía del cuerpo se inscribe en una anatomía política, en donde interactúan las esferas de lo íntimo y privado, con lo público y exterior, por lo que todo sujeto experimenta a través de su cuerpo todo tipo de sentimientos, sensaciones, emociones y placeres, que a su vez están condicionadas por actitudes y comportamientos moldeados por la cultura. De tal modo que las relaciones en torno a la sexualidad producen en la cotidianeidad "representaciones, símbolos, ideas, discursos, creencias, valores, reglas, conductas, prácticas, que imprimen una dinámica particular a las interacciones entre los individuos, quienes a su vez inciden en ellas transformándolas” (15).

\section{Imaginarios fílmicos: entre la realidad y la ficción}

Para darle mayor credibilidad y verosimilitud al filme, distinguimos algunos referentes sociales que utiliza el realizador inspirados en casos $\mathrm{y}$ situaciones de la vida real. Para ello se acercó y entrevistó a Laura Zúñiga, además de que platicó y convivió con jóvenes presos de diferentes cárteles, así como con policías estatales y municipales (Ventana Latina). Es así que su película resulta una especie de docu-ficción, es decir, una trama inventada, con personajes ficticios, pero inspirada en eventos reales. En una entrevista, Gerardo Naranjo señala lo siguiente respecto al argumento y guion de su cinta: 
CATEDRAL TOMADA: Revista de crítica literaria latinoamericana / Journal of Latin American Literary Criticism Imaginarios de la violencia en el cine mexicano contemporáneo. El caso de Miss Bala de Gerardo Naranjo.

El guion original no incluía reinas de belleza y sí agentes de la DEA en México contra el crimen organizado. A esa historia también le afectó la realidad: La aprehensión de Laura Zúñiga, Miss Sinaloa 2009, nos cambió el panorama y rehicimos el guion. Encontré en ese personaje la posibilidad de ponerme en una posición más honesta para hablar de la violencia: la de la víctima. La historia de Miss Sinaloa me permitió alejarme formalmente de los criminales y no hacer una aproximación simple, como la hacen otros medios, de justificar la mente del criminal (Linares 2011).

La intención de mostrar verosimilitud en su filme se puede vislumbrar en escenas como en la que Lino extermina a un policía de la DEA. Su muerte es tortuosa, pues Lino le amarra una soga al cuello para después atar su cuerpo a la defensa de su camioneta y así arrastrarlo por terrenos pedregosos. Tras su aniquilación, el cuerpo del policía es colgado de un puente peatonal, con una manta pegada a su torso con una leyenda que dice "aprendan", mensaje evidentemente destinado a los cuerpos policiacos. La imagen de un cuerpo colgado resulta algo familiar e incluso cotidiano en el imaginario de los mexicanos, pues a través de los medios de comunicación, o incluso como testigos oculares, sabemos que los colgados de un puente traen detrás varios mensajes: drogas, venganza, juegos de poder entre los cárteles, entre otras cosas. ¿Cuántas fotografías con estas imágenes no hemos visto en los periódicos locales y nacionales, así como en los noticiarios televisivos? La cinta nos anuncia con esta secuencia que alguien ha sido torturado y el crimen organizado vinculado al narcotráfico tiene qué ver con esto.

No estamos frente a un acto violento cualquiera, nos encontramos frente a una imagen que deambula entre la ficción y la realidad, de esa realidad que aunque no la vivimos en carne propia, la experimentamos en nuestro imaginario colectivo configurado a partir de ciertos referentes que nuestra memoria recolecta por otros medios. Los medios de comunicación juegan un rol primordial en la construcción de estos referentes, pues su representación tiene una incidencia en 
los comportamientos colectivos, tanto así, que la asumimos como real, ignorando que ha pasado por filtros (ideológicos, de edición, estéticos, etc.). Sin embargo, todo medio de comunicación -tanto informativo como creativo-“escenifica siempre, en mayor o menor grado, la realidad objetiva, el "referente" social" (Imbert, Escenarios 15). Al respecto, Gerard Imbert sostiene lo siguiente:

Violencia real y violencia representada no siempre coinciden. Pueden variar de acuerdo con el tratamiento formal que dan los medios de comunicación de la realidad (su grado de sensacionalismo), lo que plantea el problema de los efectos (directos y subliminales) de los mass media y la parte del imaginario colectivo que interviene en ello. (Escenarios 15)

En la última escena, Laura termina siendo una especie de chivo expiatorio, pues es llevada a las instalaciones de la Policía Estatal en donde la presentan como presunta implicada y cómplice de las actividades delictivas de Lino y su grupo de hombres. De esta forma, ella es exhibida ante los medios de comunicación como responsable de estas actividades, sin poder defenderse. Una vez terminado el acto oficial de mostrar a los responsables, Laura es trasladada en una camioneta hacia una zona desolada de la ciudad, en donde la sacan a empujones de la camioneta. Esto nos hace deducir que Laura fue sólo un objeto mediático para representar una detención ficticia por parte de las autoridades policiacas. La vulnerabilidad de Laura radica sobre todo en la pérdida de toda autonomía para decidir sobre su persona y su cuerpo, pues es movida como pieza de ajedrez al antojo de estructuras de poder como lo es el narcotráfico y las autoridades policiacas o judiciales.

Esta escena está inspirada en el arresto de Laura Zúñiga, pues a través de varios medios periodísticos nos enteramos de su detención, por medio de fotografías y videos, en los que podemos observarla, en medio de un grupo de hombres, con la cabeza agachada, vistiendo un suéter gris, mismas características 
CATEDRAL TOMADA: Revista de crítica literaria latinoamericana / Journal of Latin American Literary Criticism Imaginarios de la violencia en el cine mexicano contemporáneo. El caso de Miss Bala de Gerardo Naranjo.

que comparte con la representación de la escena en la película. Así pues, podemos vislumbrar varias intencionalidades por parte del director para hacer referencia con ciertas eventualidades reales. La recreación y representación de dicho evento a través de la imagen fílmica incita al espectador a redondear y dar forma a aquella percepción parcial de la realidad que solemos tener. En este sentido, siguiendo la línea merleaupontiana, la visión y percepción que se nos muestra desde el arte cinematográfico "accede a mostrar parcelas invisibles de lo real en las que se sustenta la visibilidad misma (Aguilera 35).

Estos imaginarios fílmicos muestran la violencia enmarcada en la guerra contra el narcotráfico. Pero sobre todo podemos apreciar diversas formas de violencia que se desatan a partir de esta guerra: asesinatos, secuestros, abuso sexual, trata de blancas, prostitución infantil, etc. Violencias que se dan desde todos los niveles: sistémico, institucional, familiar, de pareja. Se perpetúa la violencia de género, de la pobreza, del clasismo. Los personajes de tramas como éstas, sin importar el género cinematográfico, exponen esta variedad de violencias, al convertirse en víctimas y victimarios. La corporeidad de los sujetos se convierte en el tapiz donde queda labrada la violencia: la sangre derramada, el dolor, el sufrimiento, la tortura, la inmolación, etc. La violencia se vive y se percibe a través de los cuerpos retratados en fotografías de los diarios, de los noticiarios, en las notas amarillistas que deambulan por las redes sociales. El cuerpo se convierte en un recipiente de violencias físicas y simbólicas, marcadas, mediadas y atravesadas por cuestiones como clase, género y sexualidad (Foucault 140-159). El cuerpo es reflejo de las relaciones de poder, el cuerpo se institucionaliza y se politiza, el cuerpo es íntimo y a la vez público.

\section{A modo de conclusión}

Los imaginarios son herramientas relevantes para la comprensión de las formas de percepción y autopercepción de los individuos y colectividades. $\mathrm{Su}$ 
relevancia es tal que rebasa la cuestión de la racionalidad y de la materialidad. Su existencia se fundamenta a partir de su inexistencia en la materialidad, pero se construye a partir de ella. Los imaginarios son reales en un sentido fenomenológico en tanto los construimos a partir de nuestras percepciones intelectuales y sensoriales, construimos creencias que son compartidas y a veces confrontadas entre nuestros semejantes.

El cine resulta un medio paradigmático para explicar las experiencias de los sujetos con su entorno, de cómo se perciben, de cómo se imaginan, de cómo se asumen como algo real o verdadero en tanto lo viven a través de nuestros sentidos. O bien, de cómo los deseos, miedos, obsesiones, repulsiones, etc., condicionan el modo en que se percibe la realidad. A su vez, las imágenes cinematográficas están determinadas por un trasfondo ideológico y cultural de los creadores de éstas, las cuales son consumidas por un espectador que al igual que los autores, filtra e interioriza dichas imágenes en función de su contexto social y de su modo de percibir el mundo.

La película de Naranjo no sólo resulta singular y relevante por sus recursos estéticos y narrativos, sino por la forma de condensar imaginarios sociales que muy posiblemente se perciben entre los ciudadanos. La cinta recrea los intersticios entre la violencia estructural y la violencia subjetiva, sin caer en obviedades, jugando con un estilo estético de la violencia particular que nos transmite la angustia constante que padece Laura sin caer en lo grotesco, con técnicas como el fuera de campo, con una iluminación más de tipo naturalista y la relevancia de los efectos sonoros, así como del tipo de encuadres, creados con dureza, siempre muy próximos a la protagonista. Este filme nos lleva de los hechos históricos con tintes de horror, a la conciencia subjetiva del horror de un sujeto ordinario, sin dilemas morales, ni justificación de sus actos. Aquí, tanto víctimas como victimarios, se pueden repensar como sujetos históricos vulnerables ante la violencia estructural y sistémica.

Para concluir, podemos decir que la violencia en el mundo de la representación cinematográfica es un elemento polivalente y multifuncional, 
CAtedral Tomada: Revista de crítica literaria latinoamericana / Journal of Latin American Literary Criticism Imaginarios de la violencia en el cine mexicano contemporáneo. El caso de Miss Bala de Gerardo Naranjo.

dependiendo del género cinematográfico (western, cine bélico, noir, serie B, acción, espionaje, gore, etc.), de los recursos narrativos y de las formas estéticas, así como de contenidos ideológicos y morales, entre otros aspectos. Asimismo, la violencia en el cine puede convertirse tanto en un medio como en un fin (Imbert, Cine e imaginarios, 336). La violencia se ha convertido en un asunto complejo y polémico en los discursos fílmicos por sus implicaciones en el mundo de lo ético, moral, social, bélico. Sin embargo, en términos cinematográficos, ha derivado en una especie de género apabullante, pues éste abarca una diversidad de formas que va desde la violencia sádica hasta la lúdica, de lo repulsivo a lo fascinante, por lo que se puede hablar de una estetización de la violencia, como "un proceso mediante el cual un objeto crea un cierto placer espectatorial [y sensorial] [...]. El peligro de este tipo de procesos es la trivialización: el convertir la violencia en objeto banal, objeto de consumo, lo mismo que otros bienes materiales o simbólicos, y establecer una relación placentera" (336).

En el ámbito de lo ético, sigue resultando controversial el tema de la violencia y su uso audiovisual en el cine y en el caso de México, profundiza el debate sobre mostrar o no mostrar, representar o no representar, imaginar o no imaginar la situación alarmante de violencia social que vivimos como sociedad y como mexicanos. Finalmente, se trata de una violencia vinculada a la memoria histórica, reforzada por imaginarios colectivos, de cómo nosotros como sujetos sociales e históricos asumimos e interiorizamos el horror de la violencia, del camino que toma el horror de los hechos para internarnos en el horror de los sujetos. Porque independientemente de ser testigos directos o no de dichos fenómenos de violencia, se respira un halo de inseguridad, miedo y temor que legitima estos imaginarios de la violencia en nuestra sociedad. 
CATEDRAL TOMADA: Revista literaria latinoamericana / Journal of Latin American Literary Criticism Mayté Murillo

\section{Bibliografía}

Aguilera Vita, Sergio. "Aproximaciones al pensamiento del cine con MerleauPonty y Godard”, NAWI. Arte, Diseño, Comunicación, vol. 1, núm. 1, enero 2017, pp. 13-28.

Baczko, Bronislaw. Los imaginarios sociales. Memorias y esperanzas colectivas. Ediciones Nueva Visión, 1991.

Barthes, Roland. Lo obvio y lo obtuso. Imágenes, gestos y voces. Paidós, 2009.

Butler, Judith. Marcos de guerra. Las vidas lloradas. Paidós, 2009.

Caballero, Jorge. "Narco y violencia, en Cannes con Miss Bala, de Gerardo Naranjo". La Jornada. (15 abril 2011). www.jornada.unam.mx/2011/04/15/espectaculos/a10n1esp.

Calvo, Alejandro G., “'Miss Bala': Entrevista a Gerardo Naranjo y Stephanie Sigman”, Sensacine (11 mayo 2012). www.sensacine.com/noticias/cine/noticia-18506203/

Castillo, Gustavo y Javier Valdez. "En su mejor momento, miss Sinaloa se vinculó con un pesado de Navolato". La Jornada (5 enero 2009).

www.jornada.unam.mx/2009/01/05/index.php?section $=$ politica $\&$ article $=005 \mathrm{n}$ 1 pol.

Castoriadis, Cornelius. Los dominios del hombre: encrucijadas del laberinto. Gedisa, 1995.

Comisión Mexicana de Defensa y Promoción de los Derechos Humanos, a. c., "Violaciones graves a derechos humanos en la guerra contra las drogas en México". www.cmdpdh.org/publicaciones-pdf/cmdpdh-violaciones-gravesa-ddhh-en-la-guerra-contra-las-drogas-en-mexico.pdf

Cruz, Pablo, Geminiano Pineda, Gael García Bernal y Diego Luna (productores), Gerardo Naranjo, (director). (2011). Miss Bala [Cinta cinematográfica]. México-Estados Unidos: Canana Films, Canana Films / FOX Internacional Productions / Instituto Mexicano de Cinematografía (IMCINE) / Consejo Nacional para la Cultura y las Artes (CONACULTA) / FIDECINE / Promecap.

Deleuze, Gilles, La imagen-tiempo. Estudios sobre cine 2, Barcelona, Ediciones Paidós, 1987.Foucault, Michel. Historia de la sexualidad. La voluntad de saber. Vol. 1. México: siglo veintiuno editores, 2000.

Fagetti, Antonella. Mujeres anónimas. Del cuerpo simbolizado a la sexualidad constreñida. Instituto de Ciencias Sociales y Humanidades-BUAP, 2006.

Filmaffinity España. "Miss Bala". www.filmaffinity.com/es/film864366.html.

González Requena, Jesús. "El ideal ilustrado y el fin del tabú”. Tabú, la sombra de lo prohibido, innombrable y contaminante. Ensayos de cine, filosofía y literatura, Festival Internacional de Cine de Gijón. Vicente Domínguez, editor. Madrid: Ocho y medio, Libros de Cine, 2005. 228-242.

Herrera, Claudia, Jesús Aranda. "Calderón defiende el operativo en Michoacán y afirma que es exitoso", La Jornada (20 diciembre 2011). 
CATEDRAL TOMADA: Revista de crítica literaria latinoamericana / Journal of Latin American Literary Criticism Imaginarios de la violencia en el cine mexicano contemporáneo. El caso de Miss Bala de Gerardo Naranjo.

www.jornada.unam.mx/2006/12/20/index.php?section=politica\&article $=01$ 6 n 1 pol

Imbert, Gérard. Cine e imaginarios sociales: el cine posmoderno como experiencia de los límites (1990-2010). Cátedra, 2010.

. Los escenarios de la violencia. Icaria, 1992.

Instituto Nacional de Geografía y Estadística, "Encuesta Nacional de Victimización y Percepción sobre Seguridad Pública 2012”. Inegi.org. www.beta.inegi.org.mx/temas/percepcion/

Le Goff, "Las mentalidades. Una historia ambigua", en Pierre Nora y Jacques Le Goff, Hacer la historia, Editorial LAIA, 1974.

ares.unimet.edu.ve/derecho/fpep12/apoyo/Las\%20mentalidades.pdf

Linares Cruz, Mariana. "Miss Bala, entre la ficción y el documental", Animal Político (septiembre 2011). www.animalpolitico.com/2011/09/miss-balaentre-la-ficcion-y-el-documental/

Lipovetsky, Gilles y Jean Serroy, La pantalla global. Cultura mediática y cine en la era hipermoderna, Barcelona, Anagrama, 2009.

Lucero, Jorge Nicolás, "Movimiento de la representación: Merleau-Ponty y el cine como modelo ontológico", Investigaciones Fenomenológicas, n. 12, 2014, pp. 117-136.

Merleau-Ponty, Maurice. Fenomenología de la percepción. Origen/Planeta, 1985. Metacritic. "Miss Bala". www.metacritic.com/movie/miss-bala.

Morin, Edgar. El cine o el hombre imaginario. Paidós, 2001.

Olivares Alonso, Emir. "La guerra de Calderón contra el narco, causa del alza en la violencia y homicidios". La Jornada (5 febrero 2013). www.jornada.unam.mx/2013/02/05/politica/016n1pol.

Peña Martínez, Francisco de la. Imaginarios fílmicos, cultura y subjetividad. Por un análisis antropológico del cine. Ediciones Navarra, 2014.

Rotten tomatoes. "Miss Bala". www.rottentomatoes.com/m/miss_bala_2011/.

"Seis años después: miles de muertos y un Estado más vulnerable", Aristegui

Noticias. aristeguinoticias.com/2611/mexico/seis-anos-despues-miles-demuertos-y-un-estado-mas-vulnerable/.

Solares, Blanca. "Aproximación a la noción de Imaginario", Revista Mexicana de Ciencias Políticas y Sociales, 2006, pp. 129-141.

Taylor, Charles. Imaginarios sociales modernos. Paidós Básica, 2006.

Ventana Latina. Revista Cultural, (11 octubre 2011) www.ventanalatina.co.uk/2011/10/entrevista-gerardo-naranjo/

Zavala, Lauro. "La representación de la violencia física en el cine de ficción". Versión. Estudios de Comunicación y Política (29 abril 2012): 1-13. . "El universo como diálogo intertextual". Semiótica preliminar. Ensayos y conjeturas. Fondo Editorial Estado de México, 2014.

Žižek, Slavoj. Sobre la violencia. Seis reflexiones. Paidós, 2009.

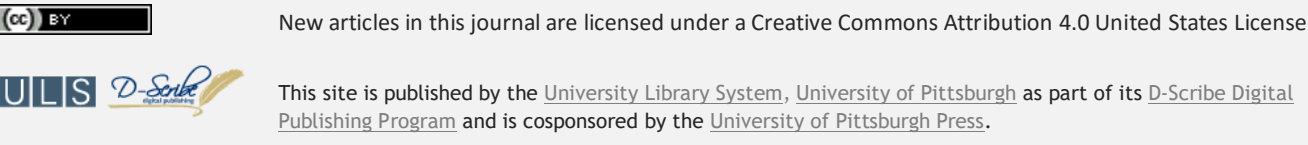

